\title{
Erratum to: Publication bias in the German social sciences: an application of the caliper test to three top-tier German social science journals
}

\author{
Carl C. Berning ${ }^{1} \cdot$ Bernd Wei $^{2}$
}

\section{Erratum to: Qual Quant DOI 10.1007/s11135-015-0182-4}

Table 2 has been published incorrectly in the original article. The correct version of the table is provided below.

Table 2 Distribution of author characteristics

\begin{tabular}{lcrcc}
\hline Authorship & KZfSS & ZfS & PVS & Row total \\
\hline Single-authored & & & & \\
Nongraduate & 1 & 0 & 0 & 1 \\
Graduate & 9 & 5 & 4 & 18 \\
Ph.D. & 19 & 11 & 10 & 40 \\
Professor & 3 & 4 & 3 & 10 \\
Co-authored total & 32 & 34 & 21 & 87 \\
Total & 64 & 54 & 38 & 156 \\
\hline
\end{tabular}

The online version of the original article can be found under doi:10.1007/s11135-015-0182-4.

Carl C. Berning

berning@politik.uni-mainz.de

Bernd Weiß

bernd.weiss@uni-koeln.de

1 Department of Political Science, Johannes Gutenberg University of Mainz, Jakob-Welder-Weg 12, 55128 Mainz, Germany

2 Institute of Sociology and Social Psychology, University of Cologne, Greinstr. 2, 50939 Cologne, Germany 
Consequently, the sentence "The majority of articles are authored by Ph.D.s and about 44 $\%$ of the 156 articles were written by more than one author." that refers to Table 2 in the texts on the same page should read as "The majority of articles are authored by Ph.D.s and about $56 \%$ of the 156 articles were written by more than one author". 